\title{
Mechanical Behavior of Asphalt Mastics Produced Using Waste Stone Sawdust
}

\author{
Ghazi G. Al-Khateeb ${ }^{D},{ }^{1}$ Taisir S. Khedaywi, ${ }^{1}$ and Motaz F. Irfaeya ${ }^{2}$ \\ ${ }^{1}$ Department of Civil Engineering, Jordan University of Science and Technology, P.O. Box 3030, Irbid 22110, Jordan \\ ${ }^{2}$ Skills Co. for Engineering Services, Al-Khaleel, West Bank, State of Palestine \\ Correspondence should be addressed to Ghazi G. Al-Khateeb; ggalkhateeb@just.edu.jo
}

Received 31 December 2017; Revised 11 March 2018; Accepted 2 May 2018; Published 27 June 2018

Academic Editor: Ana S. Guimarães

Copyright (c) 2018 Ghazi G. Al-Khateeb et al. This is an open access article distributed under the Creative Commons Attribution License, which permits unrestricted use, distribution, and reproduction in any medium, provided the original work is properly cited.

\begin{abstract}
This study intended to evaluate the use of waste stone sawdust filler with asphalt binders and compare the mechanical properties of the waste filler-asphalt mastic with those of the asphalt mastic produced using the typical limestone filler. The mastics were prepared at four filler-to-asphalt ratios by volume of asphalt binder: 0.05, 0.10, 0.20, and 0.30. A dynamic shear rheometer (DSR) strain-controlled frequency sweep test was used to evaluate the properties of the control asphalt binder and the mastics. The test used a constant strain of $10 \%$ and loading frequencies of $10,5.6,3.1,1.78,1.0,0.56,0.31,0.178$, and $0.1 \mathrm{~Hz}$ and was conducted at wide range of temperatures: $10,20,30,40,50,60$, and $70^{\circ} \mathrm{C}$. The test measured the complex shear modulus $\left(G^{*}\right)$ value and the phase angle for the binder and the mastics. The findings of this study showed that the stone sawdust filler demonstrated higher resistance to fatigue and rutting behavior than the limestone filler. However, the elastic behavior of the two asphalt mastics was nearly similar and increased with the increase in volume ratio. It was also found that the best-fit model described the relationship between the volume ratio and each of $\left|G^{*}\right| / \sin \delta$ and $\left|G^{*}\right| \cos \delta$, and the mastic-to-binder modulus ratio was the exponential model with high coefficient of determination $\left(r^{2}\right)$. The differences in the $G^{*}$ value between the limestone filler and the stone sawdust filler were relatively insignificant particularly at low loading frequencies and high temperatures. Finally, the mastic-to-binder modulus ratio decreased with the increase in loading frequency.
\end{abstract}

\section{Background}

Although asphalt mixture is approximately composed of only $5 \%$ asphalt binder and the remaining is aggregate, the mechanical properties and behavior of asphalt binder affect significantly the properties of asphalt mixture and hence play a big role in the performance of asphalt pavements.

The complexity of asphalt binder comes from the viscoelastic nature of this material. Its properties and behavior are time and temperature dependent. In addition, the mode of loading impacts this behavior. High stiffness and elastic behaviors are desired properties for asphalt binders used in hotmix asphalt design and production. High stiffness is required to resist rutting under heavy loads in pavements. On the other hand, elastic behavior is also needed to recover and heal part of the deformations in pavements under loading to minimize fatigue cracking. Researchers in the asphalt technology field have been always attempting to enhance and optimize properties of asphalt used in the pavement construction.

Modification of asphalt binders is done by utilizing several modifiers that are available on a wide spectrum in the industry. Some of these modifiers are manufactured so that they are used in the asphalt technology at a feasible cost. However, other modifiers are waste or recycled materials that can be used in asphalt to serve twofold purpose: (1) enhancing the properties of asphalt and (2) helping to clean environment.

Many research studies have used waste materials and available filler materials to enhance the properties of asphalt binders and mixtures. Waste materials such as rubber of waste tires, oil shale ash, medical ash, and toner waste [1-4] have been used to enhance the properties of asphalt binders 
used in the hot-mix asphalt technology. In addition, some researchers took advantage of agricultural tree and plant waste such as the empty fruit bunch of date and oil palm trees [5] to produce cellulose fiber to be used as additives in the asphalt binder.

Other research studies have been conducted to investigate the effect of mineral fillers on the mechanical properties of asphalt binders. The complex characteristics of fatigue behavior were evaluated in a study of asphalt binders and mastics produced using limestone and hydrated lime fillers [6]. The effect of filler-to-asphalt ratio on low- and high-temperature properties of asphalt mastics using mineral fillers was studied [7]; it was found that the optimum range of the filler-to-asphalt ratio is $0.9-1.4$ to balance the low- and high-temperature properties according to the study. The effect of basalt and hydrated lime fillers on the behavior of rutting, fracture, and thermal cracking resistance of asphalt mastics was investigated [8]; the addition of hydrated lime improved the low-temperature and rutting performance as well as fracture resistance.

The Portland cement filler was used to modify the asphalt binder [9]. It was shown that the increase in the cement-to-asphalt ratio improved the Superpave high performance grade and the rutting resistance of asphalt binders by increasing the stiffness and the $G^{*} / \sin \delta$ parameter. In a study that used waste materials in asphalt concrete mixtures [10], it was found that marble powder and fly ash could be used as filler materials instead of stone powder in the asphalt concrete, and rubber particles of the size between no. 4 and no. 200 showed the best results in terms of the indirect tensile test.

Rutting and fatigue are considered two major distresses that occur in asphalt pavements. The asphalt binder plays a big role in the performance of asphalt mixture and hence in controlling the two distresses. Different modifiers and fillers were tried in the literature as seen in the above paragraphs to enhance the mechanical properties of asphalt binders. In this study, a waste material (the stone sawdust) is used to achieve two objectives: to enhance and improve the mechanical properties of asphalt binders that are related to rutting and fatigue resistance, and at the same time to get rid off the waste material and keep the environment clean.

There are no available statistical data about the amount of stone sawdust waste in Jordan since this waste is not among the waste types being managed by municipal authorities or private sector. However, burnt stone slurry (a solid waste powder) has been reported in [11] to be about 53000 tons per year collected from 1000 quarries and tiles factories in Jordan. The cost of transporting and dumping this big amount of waste is about 1 million dollars.

In this study, the waste stone sawdust collected from stonemanufacturing sites for building purposes was used as a filler material in the asphalt binder to investigate the mechanical properties of the produced asphalt mastics. The waste stone sawdust is retained from stone fabrication. Hence, this waste material is the material generated from the same rock quarries as for the limestone filler typically used in the production of hot-mix asphalt in the area. For this purpose, a comparison between the two fillers in this study was made.

\section{Objectives}

The main objectives of this study are as follows:

(1) To investigate the effect of stone sawdust as a filler material in the filler-asphalt mastic

(2) To assess the effect of stone sawdust on the mechanical properties of asphalt binders

(3) To check whether the stone sawdust fillers can be a replacement for the limestone filler in asphalt mastics by comparing the behavior of these two fillers when mixed with asphalt.

\section{Asphalt Materials and Fillers Used in the Study}

The 60/70-penetration grade asphalt binder was used in this study. This asphalt binder is the most common asphalt binder widely used in producing asphalt mixtures for highway asphalt pavements in Jordan. The properties of the asphalt binder were determined and are summarized in Table 1.

Two filler materials were utilized in the study: limestone and stone sawdust. These materials are considered waste materials from construction sites in Jordan. The limestone was obtained from a local quarry, and the stone sawdust was obtained from the manufacturing process of building stones. Both materials were sieved using wet sieving process. The material portion passing sieve no. $200(75 \mu \mathrm{m})$ was obtained and dried in an oven for approximately 24 hours at an intermediate temperature.

The specific gravity, plasticity index, and angularity were measured for the two filler materials. The results of these properties are shown in Table 2.

\section{Methodology}

4.1. Preparation of Filler-Asphalt Mastics. The preparation of the filler-asphalt mastic (limestone-asphalt mastic and stone sawdust-asphalt mastic) samples was done according to the following procedure. The filler material was heated for one hour in an oven at $150^{\circ} \mathrm{C}$ in order to simulate the conditions during the mixing process. The asphalt binder was also heated at the same temperature $\left(150^{\circ} \mathrm{C}\right)$ for about 20 minutes in small containers. Mixing was done manually for about 15 minutes by gradually adding the filler to the asphalt binder and mixing using a glass rod to ensure homogeneity and to prevent excessive balling. The filler-asphalt mastic was produced at four volume ratios (VRs): $0.05,0.10,0.20$, and 0.30 by volume of the asphalt binder.

To prepare the dynamic shear rheometer (DSR) test samples of the asphalt binder and the filler-asphalt mastic, the asphalt material (binder or mastic) was heated in an oven at a temperature of about $150^{\circ} \mathrm{C}$ until it became sufficiently fluid to be poured. The standard silicone mold having a diameter of $25 \mathrm{~mm}$ was used to produce the asphalt samples for DSR testing (Figure 1). The sample was allowed to cool for a proper period of time until it became solid enough to be removed from the mold. 
TABLE 1: Original asphalt binder properties.

\begin{tabular}{lcc}
\hline & Asphalt binder 60/70 & \\
\multicolumn{1}{c}{ Test } & Result \\
\hline Penetration $(\mathrm{dmm})$ & 65 \\
Ductility $(\mathrm{cm})$ & 106 \\
Specific gravity & 1.00 \\
Flash point $\left({ }^{\circ} \mathrm{C}\right)$ & 316 \\
Softening point $\left({ }^{\circ} \mathrm{C}\right)$ & 54 \\
\hline
\end{tabular}

TABle 2: Properties of fillers used in the study.

\begin{tabular}{lcc}
\hline \multirow{2}{*}{ Property } & \multicolumn{2}{c}{ Filler material } \\
& Limestone & Stone sawdust \\
\hline Specific gravity & 2.610 & 2.460 \\
Plasticity index & Nonplastic & Nonplastic \\
Angularity & $67 \%$ & $61 \%$ \\
\hline
\end{tabular}

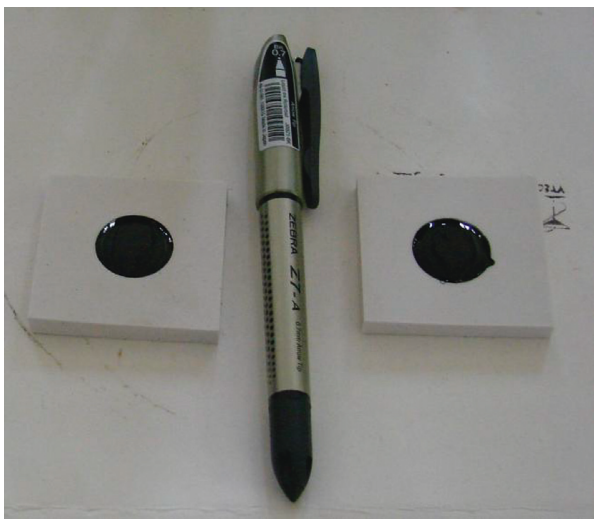

FIGURE 1: Samples for DSR testing.

4.2. Frequency Sweep Tests of Asphalt Binders and Mastics. The DSR (Figure 2) was used to measure the mechanical properties of the control asphalt binder and the filler-asphalt mastics at a variety of temperatures. The asphalt sample (binder or mastic) was placed into the device between two plates, and the gap (the thickness of the sample) was set to $1 \mathrm{~mm}$ (Figure 3). The sample was tested by applying a sinusoidal dynamic strain using the oscillating upper plate. A strain-controlled frequency sweep test was used. The constant strain was $10 \%$, and the loading frequency varied from 0.1 to $10 \mathrm{~Hz}$ and covered the values: $0.1,0.178,0.31,0.56,1.0,1.78,3.1$, 5.6 , and $10 \mathrm{~Hz}$. The test temperatures covered a wide range of temperatures $\left(10,20,30,40,50,60\right.$, and $\left.70^{\circ} \mathrm{C}\right)$. The frequency sweep testing matrix used in this study is shown in Table 3.

The complex shear modulus $\left(\left|G^{*}\right|\right)$ value and the phase angle $(\delta)$ were recorded during the frequency sweep test. The shear modulus represents the stiffness of the asphalt material that is responsible for the resistance to deformation (rutting) under continuous shearing of the binder at the desired temperature and loading frequency. On the other hand, the phase angle represents the time lag between the elastic and viscous response of the asphalt material that is behaving as a viscoelastic material.

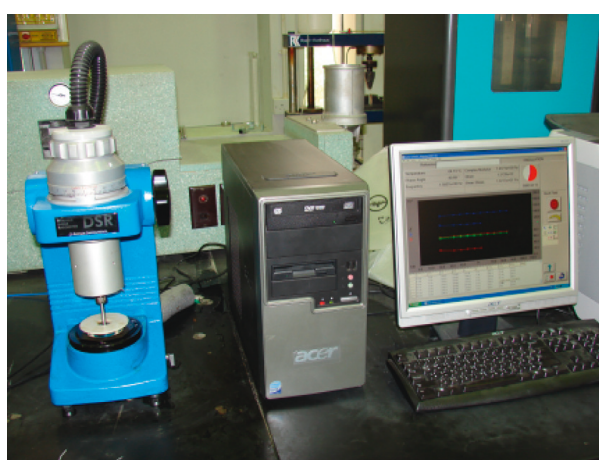

FIgure 2: Dynamic shear rheometer (DSR).

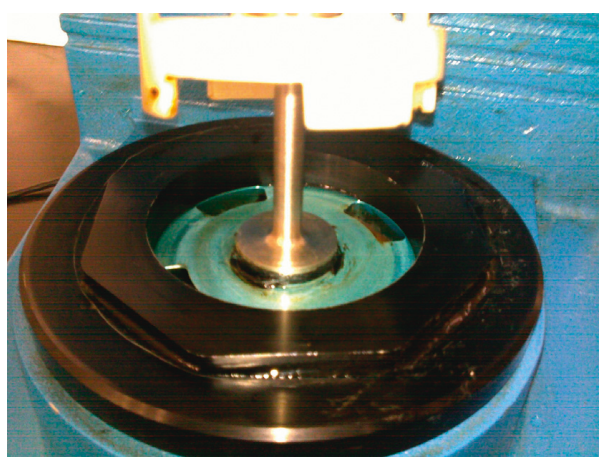

FIgURE 3: Sample sandwiched between the two plates.

TABLE 3: Testing matrix.

\begin{tabular}{lcc}
\hline Test variable & Number & Values \\
\hline Volume ratio & 5 & $0.00,0.05,0.10,0.20$, and 0.30 \\
Asphalt binder & 1 & $60 / 70$-penetration grade \\
Filler type & 2 & Limestone and stone sawdust \\
Loading frequency & 9 & $0.1,0.178,0.31,0.56,1.0,1.78$, \\
Temperature & 7 & $10,20,30,40,50,60$, and $70^{\circ} \mathrm{C}$ \\
Replicates & 2 & Two replicates \\
Total number of tests & \multicolumn{2}{c}{$5 \times 1 \times 2 \times 9 \times 7 \times 2=1260$ tests } \\
\hline
\end{tabular}

4.3. Fatigue, Rutting, and Elastic Parameters Used in the Analysis. In the Superpave system [12], the fatigue and rutting parameters used in the asphalt binder performance criteria are $\left|G^{*}\right| \sin \delta$ and $\left|G^{*}\right| / \sin \delta$, respectively. $\left|G^{*}\right|$ refers to the complex shear modulus value of the asphalt binder, and $\delta$ is the phase angle value of the binder. The $\left|G^{*}\right| \sin \delta$ parameter value is obtained for the asphalt binder at intermediate temperatures to verify the fatigue performance of the binder; the maximum value specified by the Superpave is $5000 \mathrm{kPa}$ based on specified protocols and procedures that have to be done on the asphalt binder. On the other hand, the $\left|G^{*}\right| / \sin \delta$ is obtained for the asphalt binder at high temperatures to investigate the rutting behavior of the binder; the minimum value specified by the Superpave is $1.00 \mathrm{kPa}$ for original asphalt binder and $2.20 \mathrm{kPa}$ for shortterm aged binder according to the protocols described in the Superpave system. 
Additionally, the $\left|G^{*}\right| \cos \delta$ is also used in the analysis of data in this study that refers to the elastic part of the asphalt material. It is well known that the phase angle of the asphalt binder (a viscoelastic material) indicates the lag between the applied stress/strain and the resulting strain/stress; as the asphalt binder becomes more elastic, the phase angle decreases, and as the asphalt binder behaves more viscous, the phase angle increases. The horizontal component of the complex shear modulus value of the asphalt binder is $\left|G^{*}\right| \cos \delta$ that represents the elastic part of the binder; it improves as the phase angle decreases.

\section{Analysis of Data and Results}

This part presents the results and analysis of the frequency sweep test data obtained for the control asphalt binder, the limestone-asphalt mastic, and the stone sawdust-asphalt mastic [13]. The analysis includes four different aspects: the fatigue resistance, the rutting resistance, the elastic behavior, and frequency sweep test results and master curves of the control asphalt binder and the filler-asphalt mastics in addition to a comparison between limestone-asphalt mastics and stone sawdust-asphalt mastics.

5.1. Fatigue and Rutting Behaviors of Asphalt Mastics. The value of $\left|G^{*}\right| \sin \delta$ was recommended by the Superpave as a fatigue parameter of asphalt binders. As fatigue occurs at intermediate temperatures, this parameter was determined for the control asphalt binder and the two mastics at intermediate temperatures. Figures 4 and 5 illustrate the fatigue behavior of the binder and the two mastics at two low temperatures (20 and $30^{\circ} \mathrm{C}$ ) and one loading frequency $(1.78 \mathrm{~Hz})$. These figures clearly show that the two fillers increased the $\left|G^{*}\right| \sin \delta$ value and hence improved the fatigue resistance of asphalt binder with the increase in volume ratio. In general, the stone sawdust filler showed higher resistance to fatigue than the limestone.

The rutting parameter in the Superpave system is the value of $\left|G^{*}\right| / \sin \delta$. This value is measured at high temperatures (typically more than $45^{\circ} \mathrm{C}$ ) to characterize asphalt binders for rutting behavior. In this study, seven temperatures were used: three $\left(50,60\right.$, and $\left.70^{\circ} \mathrm{C}\right)$ are considered high temperatures for rutting and four $\left(10,20,30\right.$, and $\left.40^{\circ} \mathrm{C}\right)$ are considered intermediate temperatures for fatigue cracking. As the $\left|G^{*}\right|$ value gets higher, the asphalt material (asphalt binder or mastic) becomes stiffer and hence more resistant to rutting. On the other hand, as the $\delta$ value gets smaller, the asphalt material becomes more elastic and therefore more resistant to rutting due to the recovery of part of the deformation.

Figures 6 and 7 show the rutting behavior of the control asphalt binder and the two mastics at the two extreme temperatures $\left(50\right.$ and $\left.70^{\circ} \mathrm{C}\right)$. These two figures represent only two examples at one loading frequency $(1.78 \mathrm{~Hz})$. Both figures clearly show that the fillers improved the rutting parameter with the increase in volume ratio. The stone sawdust-asphalt mastic showed higher resistance to rutting than the limestone-asphalt mastic. The relationship between $\left|G^{*}\right| / \sin \delta$ and volume ratio was found to be exponential. The exponential models with the coefficients of determination

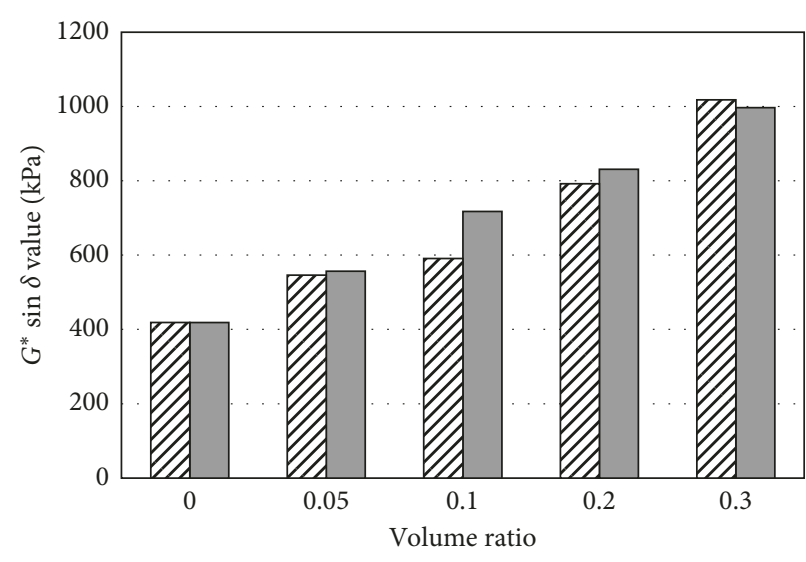

Limestone

$\square$ Stone sawdust

Figure 4: Fatigue behavior at $20^{\circ} \mathrm{C}$.

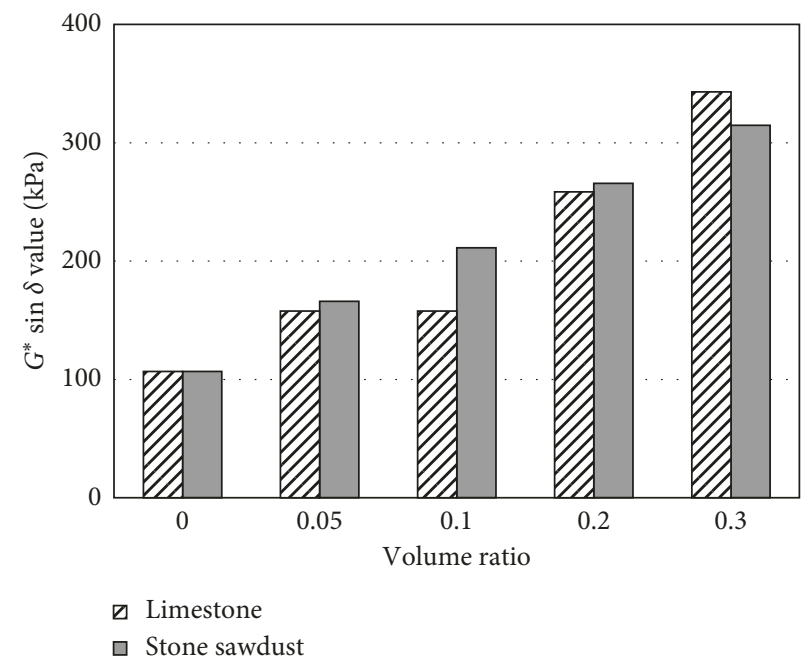

Figure 5: Fatigue behavior at $30^{\circ} \mathrm{C}$.

$\left(r^{2}\right)$ for the two mastics at all high temperatures are summarized in Tables 4 and 5 .

5.2. Elastic Behavior of Asphalt Mastics. The value of $\left|G^{*}\right| \cos \delta$ represents the elastic portion of the complex shear modulus of the asphalt material. This elastic part helps the asphalt material to resist deformation under shear loading particularly at low and intermediate temperatures. Consequently, this parameter plays a role in the healing process of deformations for rutting and fatigue cracking of asphalt.

Figures 8 and 9 demonstrate the elastic behavior $\left(\left|G^{*}\right| \cos \delta\right)$ of the original binder and the two mastics at two extreme temperatures $\left(10\right.$ and $\left.70^{\circ} \mathrm{C}\right)$, different volume concentrations $(0.0,0.05,0.10,0.20$, and 0.30$)$, and one single frequency $(1.78 \mathrm{~Hz})$.

The elastic behavior of the two asphalt mastics increased with the increase in volume ratio as shown in these two figures. The $\left|G^{*}\right| \cos \delta$ values for the stone sawdust and 


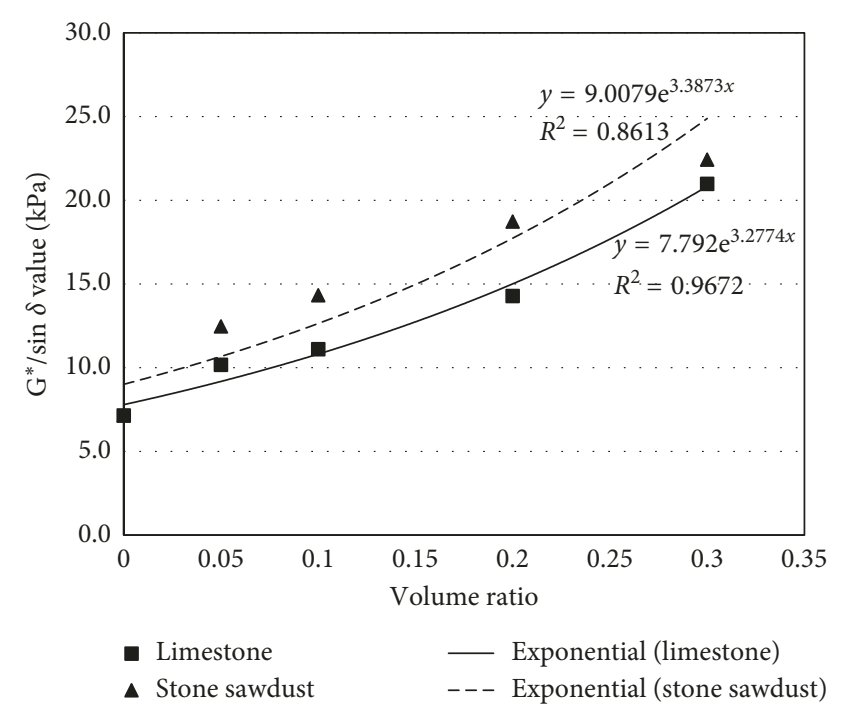

FIgURE 6: Rutting behavior of asphalt mastics at $50^{\circ} \mathrm{C}$.

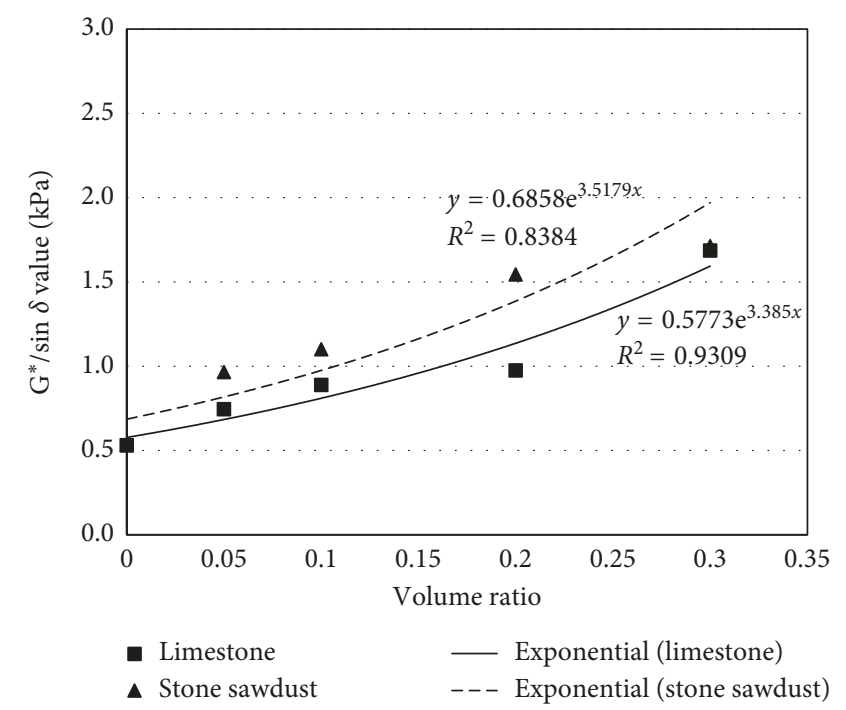

FIgURE 7: Rutting behavior of asphalt mastics at $70^{\circ} \mathrm{C}$.

TABLE 4: Relationship between $\left|G^{*}\right| / \sin \delta$ and VR for the limestoneasphalt mastic.

\begin{tabular}{lcc}
\hline Temperature $\left({ }^{\circ} \mathrm{C}\right)$ & Model & $r^{2}$ value \\
\hline 50 & $\left|G^{*}\right| / \sin \delta=7.792 e^{3.277 \mathrm{VR}}$ & 0.97 \\
60 & $\left|G^{*}\right| / \sin \delta=2.000 e^{3.423 \mathrm{VR}}$ & 0.94 \\
70 & $\left|G^{*}\right| / \sin \delta=0.577 e^{3.385 \mathrm{VR}}$ & 0.93 \\
\hline
\end{tabular}

limestone mastics were approximately similar at all frequencies and temperatures. The best-fit model that described the relationship between the volume ratio (VR) and the $\left|G^{*}\right| \cos \delta$ value is the exponential model. The coefficient of determination $\left(r^{2}\right)$ for the model was high in all cases as shown in Tables 6 and 7.

With the increase in temperature, the $\left|G^{*}\right| \cos \delta$ value decreased for the two mastics and this is typical.
TABLE 5: Relationship between $\left|G^{*}\right| / \sin \delta$ and VR for the stone sawdust-asphalt mastic.

\begin{tabular}{lcc}
\hline Temperature $\left({ }^{\circ} \mathrm{C}\right)$ & Model & $r^{2}$ value \\
\hline 50 & $\left|G^{*}\right| / \sin \delta=9.008 e^{3.387 \mathrm{VR}}$ & 0.86 \\
60 & $\left|G^{*}\right| / \sin \delta=2.358 e^{3.485 \mathrm{VR}}$ & 0.85 \\
70 & $\left|G^{*}\right| / \sin \delta=0.686 e^{3.518 \mathrm{VR}}$ & 0.84 \\
\hline
\end{tabular}

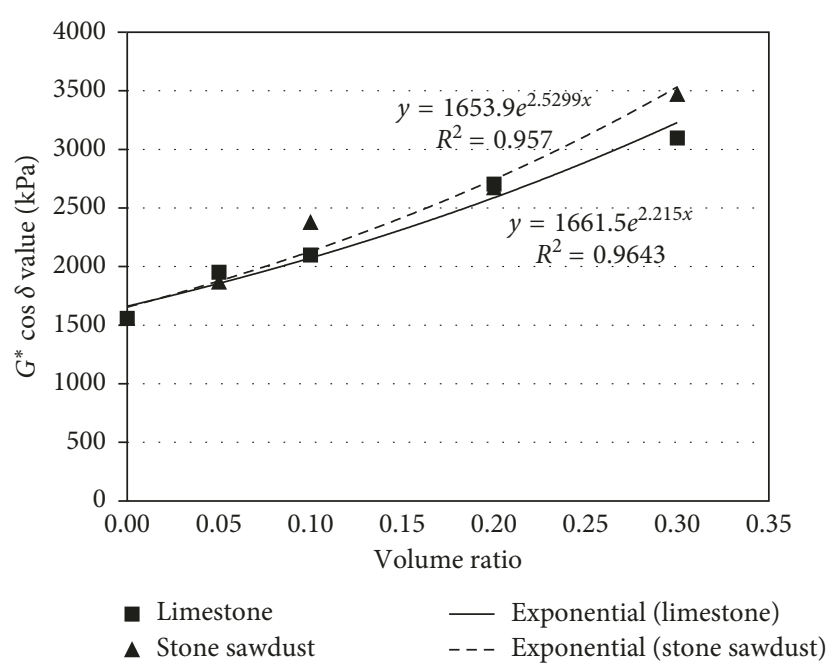

FIGURE 8: Elastic behavior of asphalt mastics at $10^{\circ} \mathrm{C}$ and $1.78 \mathrm{~Hz}$ versus VR.

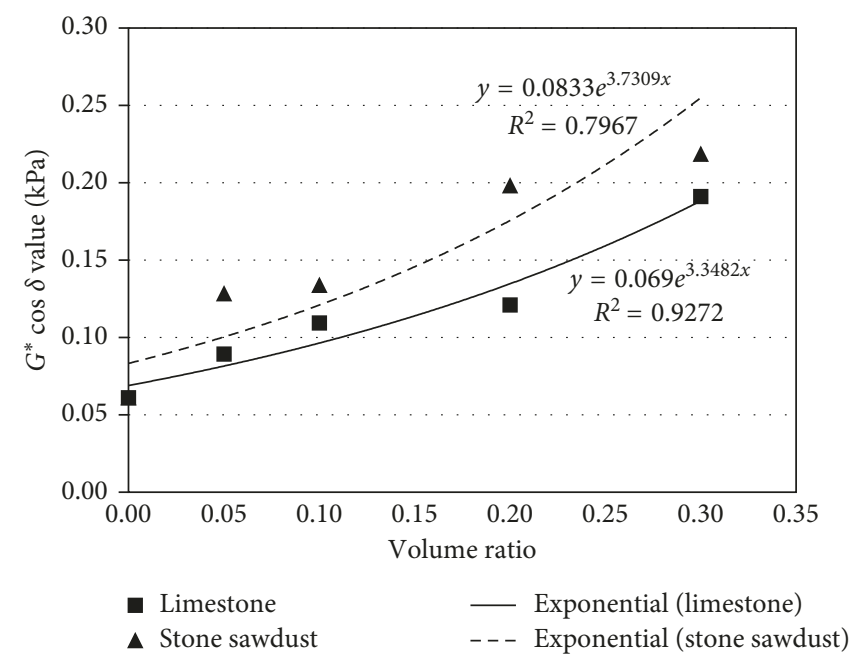

FIgURE 9: Elastic behavior of asphalt mastics at $70^{\circ} \mathrm{C}$ and $1.78 \mathrm{~Hz}$ versus VR.

Nevertheless, the rate of reduction in this value at lower temperatures was very sharp and significant compared to high temperatures as shown in Figures 10 and 11. The stone sawdust filler was compared with the limestone filler in terms of the mastic $\left|G^{*}\right| \cos \delta$. Figure 12 demonstrates this comparison for the smallest volume ratio (0.05) and the highest volume ratio (0.30) at a loading frequency of $1.78 \mathrm{~Hz}$. The figure shows that the elastic behavior of both fillerasphalt mastics is similar. This finding is important and 
TABLE 6: Relationship between $\left|G^{*}\right| \cos \delta$ and VR for the limestone mastic $(1.78 \mathrm{~Hz})$.

\begin{tabular}{lcc}
\hline Temperature $\left({ }^{\circ} \mathrm{C}\right)$ & Model & $r^{2}$ value \\
\hline 10 & $\left|G^{*}\right| \cos \delta=1661.5 e^{2.215 \mathrm{VR}}$ & 0.96 \\
20 & $\left|G^{*}\right| \cos \delta=376.1 e^{3.950 \mathrm{VR}}$ & 0.94 \\
30 & $\left|G^{*}\right| \cos \delta=66.56 e^{4.274 \mathrm{VR}}$ & 0.92 \\
40 & $\left|G^{*}\right| \cos \delta=11.92 e^{3.567 \mathrm{VR}}$ & 0.95 \\
50 & $\left|G^{*}\right| \cos \delta=2.055 e^{3.381 \mathrm{VR}}$ & 0.94 \\
60 & $\left|G^{*}\right| \cos \delta=0.3536 e^{3.570 \mathrm{VR}}$ & 0.94 \\
70 & $\left|G^{*}\right| \cos \delta=0.0690 e^{3.348 \mathrm{VR}}$ & 0.93 \\
\hline
\end{tabular}

TABLE 7: Relationship between $\left|G^{*}\right| \cos \delta$ and VR for the stone sawdust mastic $(1.78 \mathrm{~Hz})$.

\begin{tabular}{lcc}
\hline Temperature $\left({ }^{\circ} \mathrm{C}\right)$ & Model & $r^{2}$ value \\
\hline 10 & $\left|G^{*}\right| \cos \delta=1653.9 e^{2.530 \mathrm{VR}}$ & 0.96 \\
20 & $\left|G^{*}\right| \cos \delta=414.3 e^{3.562 \mathrm{VR}}$ & 0.91 \\
30 & $\left|G^{*}\right| \cos \delta=74.51 e^{3.718 \mathrm{VR}}$ & 0.87 \\
40 & $\left|G^{*}\right| \cos \delta=13.46 e^{3.392 \mathrm{VR}}$ & 0.85 \\
50 & $\left|G^{*}\right| \cos \delta=2.423 e^{3.555 \mathrm{VR}}$ & 0.81 \\
60 & $\left|G^{*}\right| \cos \delta=0.4301 e^{3.702 \mathrm{VR}}$ & 0.80 \\
70 & $\left|G^{*}\right| \cos \delta=0.0833 e^{3.731 \mathrm{VR}}$ & 0.80 \\
\hline
\end{tabular}

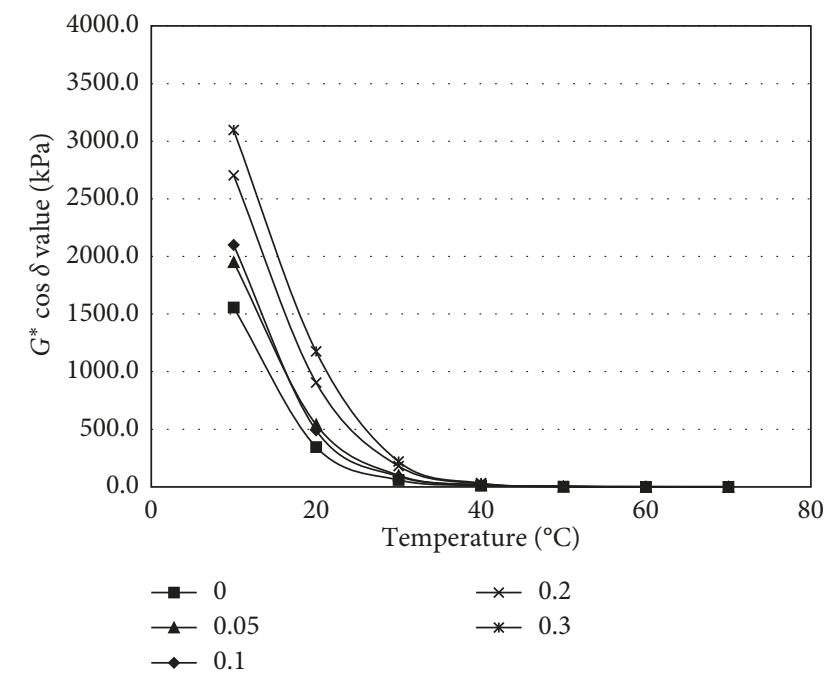

Figure 10: $\left|G^{*}\right| \cos \delta$ versus temperature for the limestone mastic $(1.78 \mathrm{~Hz})$.

indicates that the waste stone sawdust can replace the limestone filler in asphalt mix particularly that the source of the two materials is the same, which is the stone used for building and construction in the area. In other words, the other physical properties of the two materials are also the same.

\section{Frequency Sweep Test Results and Master Curves}

As the frequency sweep test was conducted at nine loading frequencies and seven temperatures, the master curves

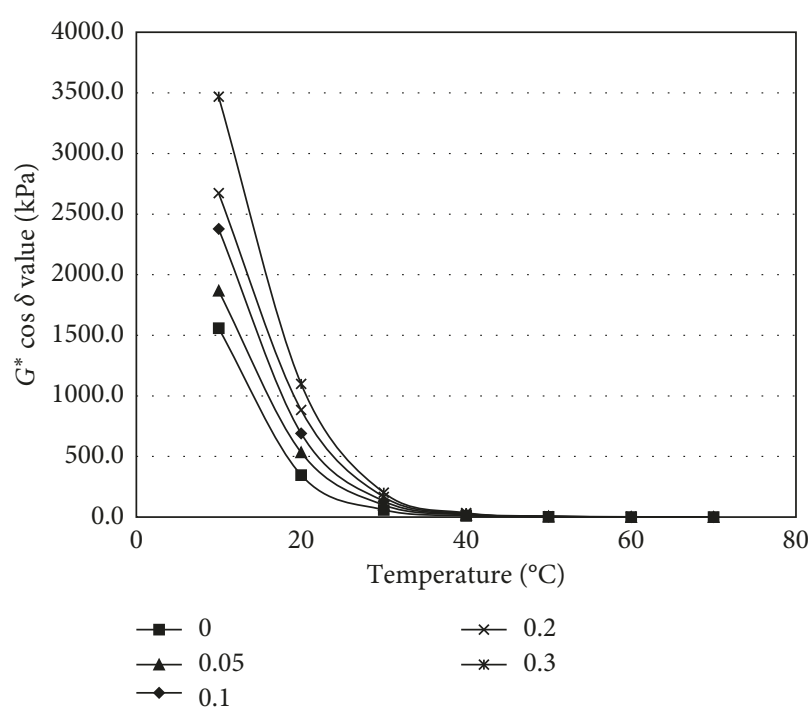

Figure 11: $\left|G^{*}\right| \cos \delta$ versus temperature for the stone sawdust mastic $(1.78 \mathrm{~Hz})$.

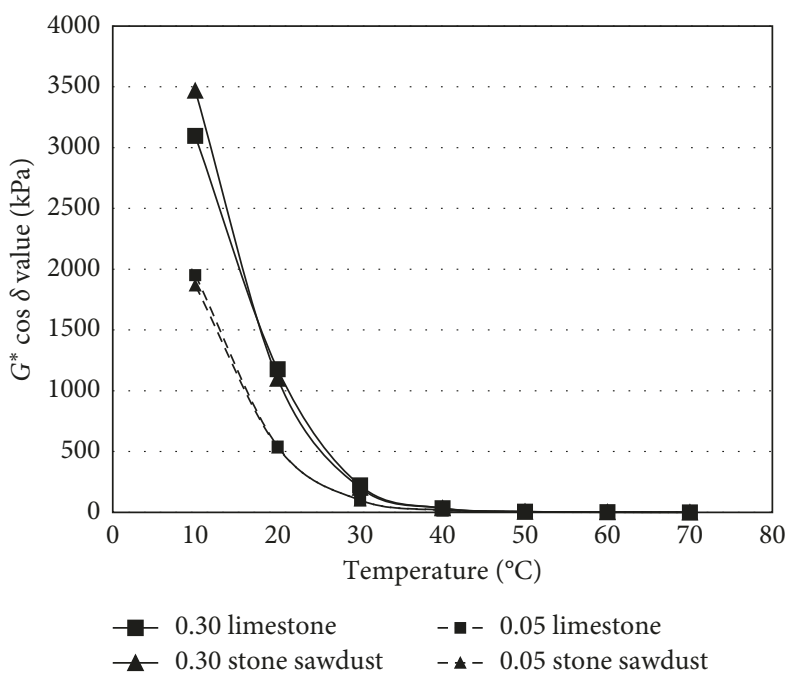

Figure 12: $\left|G^{*}\right| \cos \delta$ comparison between stone sawdust and limestone $(1.78 \mathrm{~Hz})$.

for the control binder and each of the eight filler-asphalt mastics could be obtained. Figures 13-17 show the flow curves ( $G^{*}$ value versus frequency) for the control asphalt binder, the limestone mastic, and the stone sawdust mastic (examples at 0.05 and 0.30 volume ratios).

The above flow curves show how the stiffening behavior of asphalt binder and mastic changed due to the increase in loading frequency and test temperature. In addition, the $G^{*}$ value increased due to three factors: (1) a decrease in temperature, (2) an increase in loading frequency, and (3) an increase in volume ratio.

Master curves are used to represent huge data at multitemperatures and loading frequencies such as the case in this study. One master curve for each volume ratio at a reference temperature is obtained to describe the behavior of the asphalt 


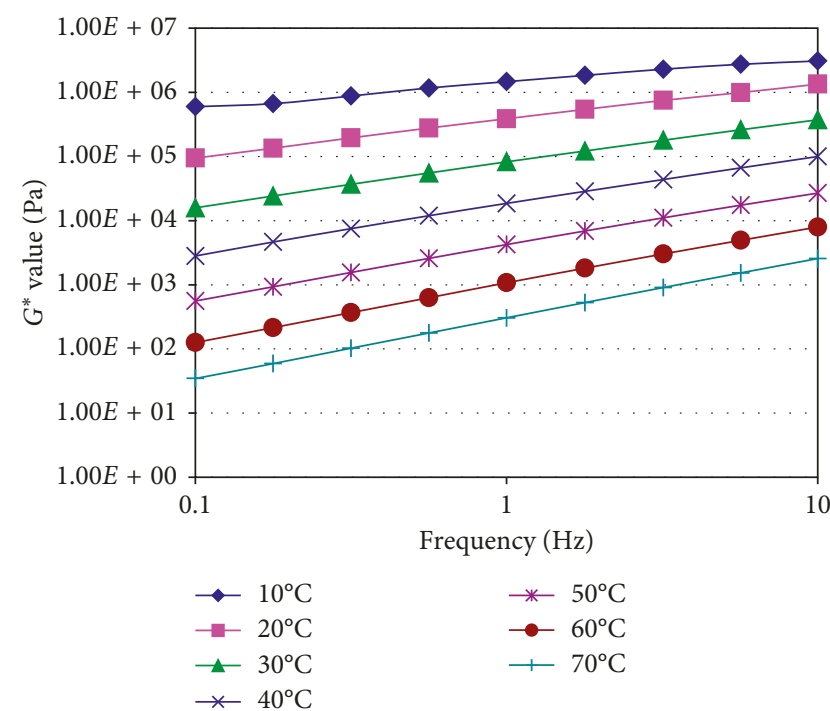

Figure 13: $G^{*}$ value versus loading frequency for the control asphalt binder.

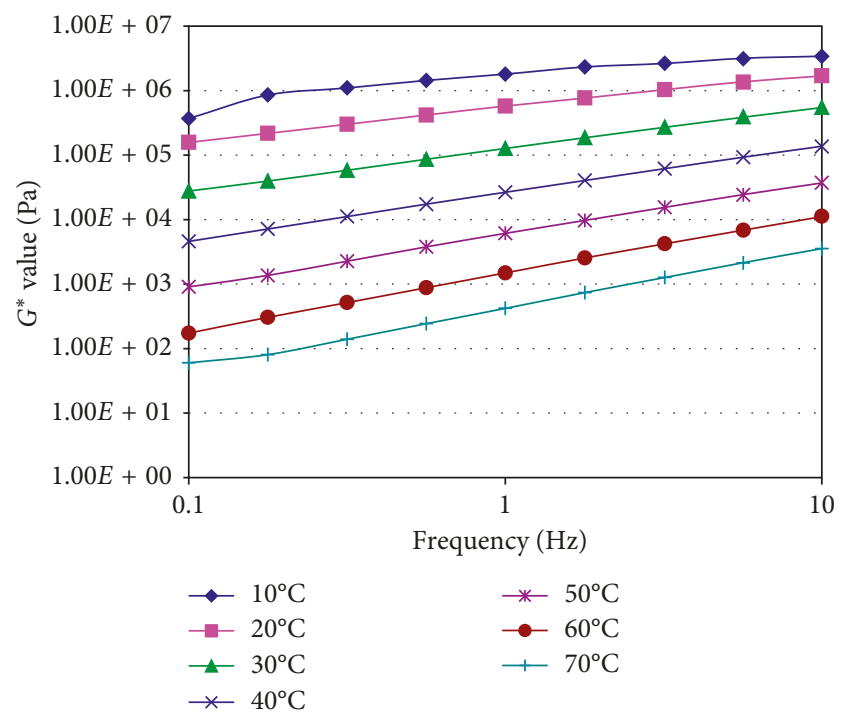

Figure 14: $G^{*}$ value versus loading frequency for the limestone mastic $(\mathrm{VR}=0.05)$.

material (asphalt binder or mastic) at a variety of temperatures and loading frequencies.

The $\left|G^{*}\right|$ master curves for the control asphalt binder and the eight filler-asphalt mastics were obtained. Using a reference temperature of $40^{\circ} \mathrm{C}$ for the master curves, the shift factors for the other temperatures were calculated for each master curve. Table 8 illustrates an example of the shift factors for the 0.05 stone sawdust mastic.

Figures 18-22 show the master curves for the two mastics at the following volume ratios: $0.00,0.05,0.10,0.20$, and 0.30 , respectively. These curves can be used easily to determine the behavior of the asphalt material at a specific frequency and temperature.

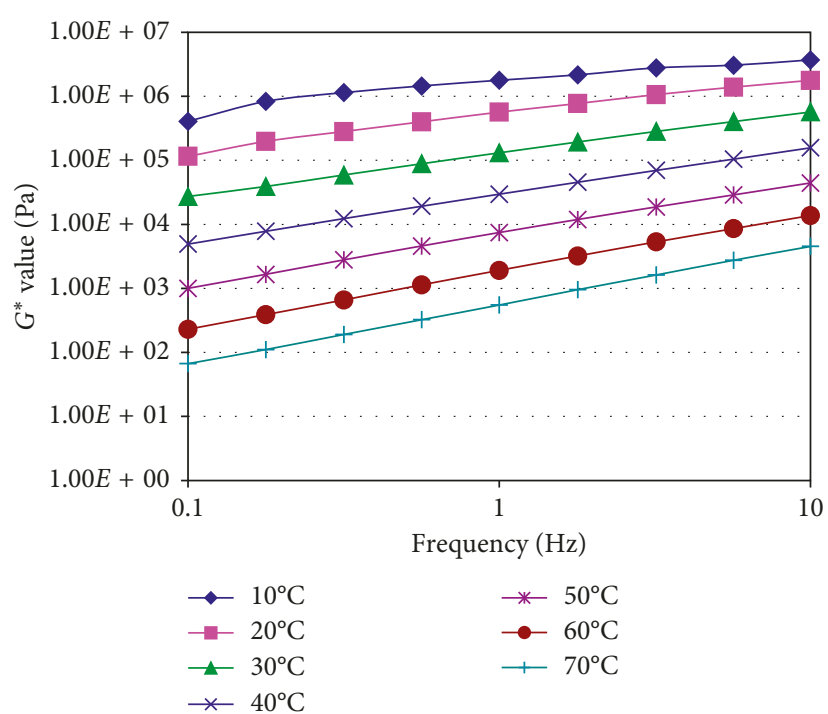

FIGURE 15: $G^{*}$ value versus loading frequency for the stone sawdust mastic $(\mathrm{VR}=0.05)$.

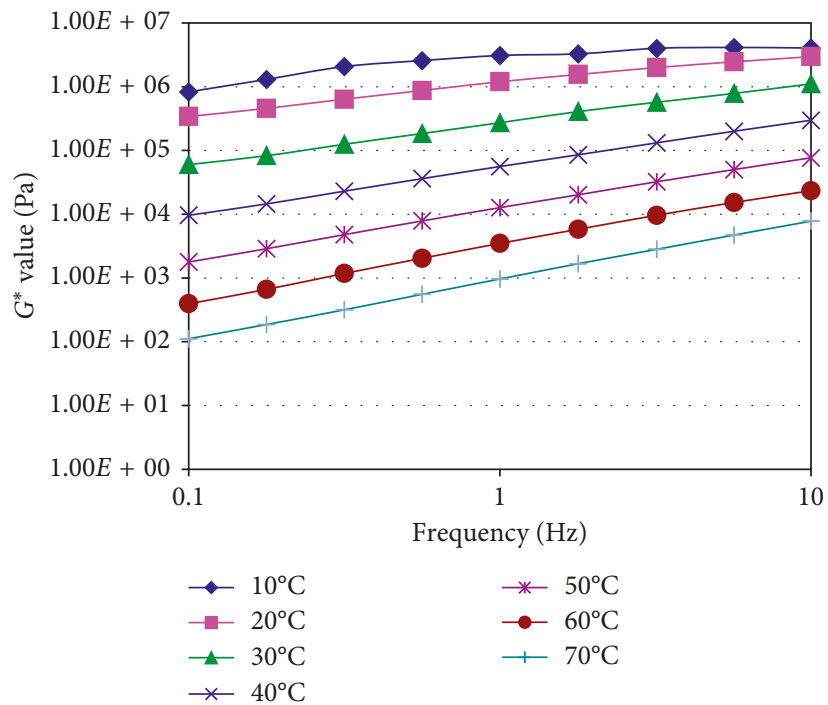

FIgURE 16: $G^{*}$ value versus loading frequency for the limestone mastic $(\mathrm{VR}=0.30)$.

The master curves of the two mastics at the four volume ratios reveal several important findings. The differences in the complex shear modulus $\left(G^{*}\right)$ value between the limestone filler and the stone sawdust filler are relatively small particularly at low reduced frequencies (i.e., at low loading frequencies and high temperatures). These differences become larger at high loading frequencies and low temperatures; yet, they are still insignificant between the two fillers. These findings again suggest that the stone sawdust may be used as alternative filler for the limestone in asphalt mixtures.

The ratio of the mastic modulus to the control asphalt binder modulus was found to decrease as the loading 


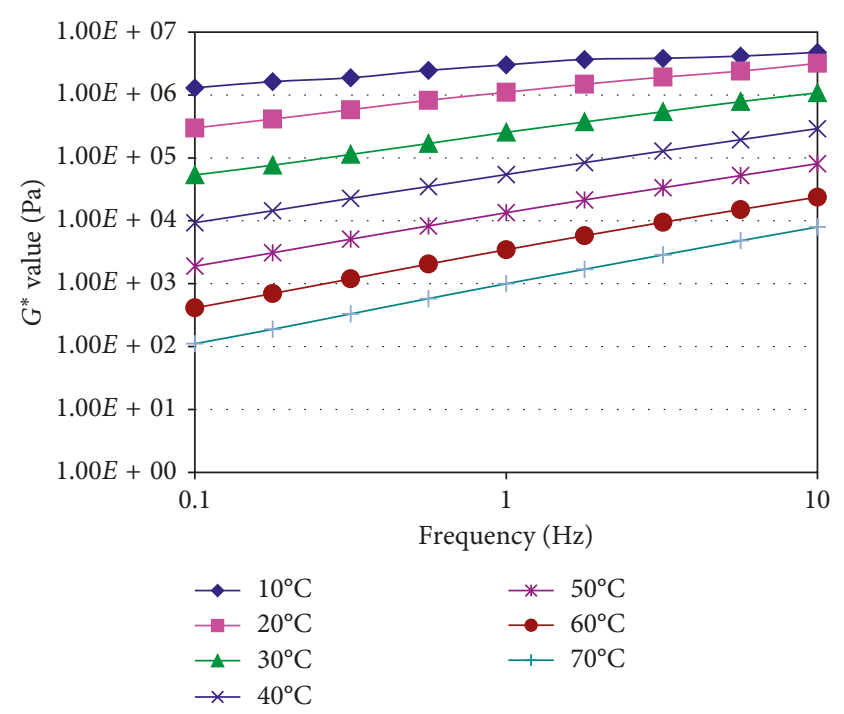

FIGURE 17: $G^{*}$ value versus loading frequency for the stone sawdust mastic $(\mathrm{VR}=0.30)$.

TABle 8: Shift factors for the 0.05 stone sawdust-asphalt mastic.

\begin{tabular}{lccccccc}
\hline Temperature $\left({ }^{\circ} \mathrm{C}\right)$ & 10 & 20 & 30 & 40 & 50 & 60 & 70 \\
$\log \left(a_{\mathrm{T}}\right)$ & 2.871 & 1.895 & 0.898 & 0 & -0.762 & -1.441 & -2.024 \\
\hline
\end{tabular}

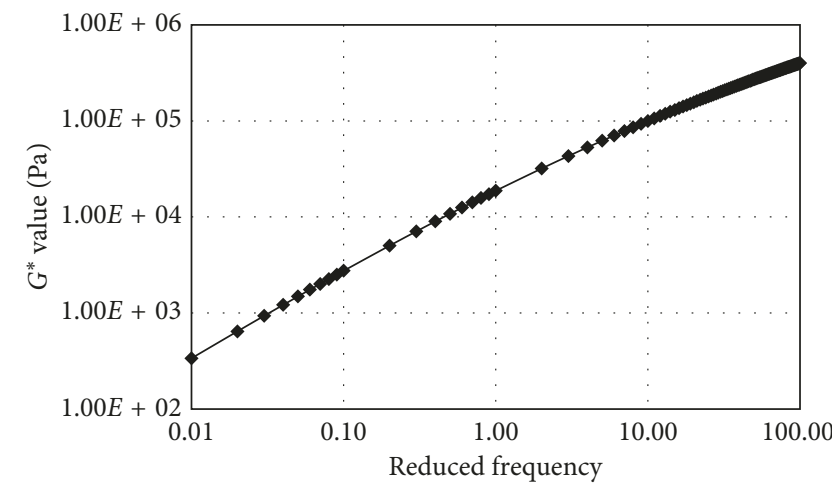

FIGURE 18: $G^{*}$ value master curve for the control asphalt binder $(\mathrm{VR}=0.00)$.

frequency increased; this is demonstrated in Figure 23. The figure shows the comparison between the two mastics at a temperature of $40^{\circ} \mathrm{C}$ and volume ratio of 0.30 . Similar trends were also obtained at the other temperatures and volume ratios.

The complex shear modulus ratio (mastic to binder) was also plotted against the volume ratio for both mastics (limestone and stone sawdust). Figure 24 illustrates this relationship for the two mastics at a temperature of $40^{\circ} \mathrm{C}$ and loading frequency of $1 \mathrm{~Hz}$. The modulus ratio increased with the increase in the volume ratio as seen in this figure. A similar trend was obtained at the other temperatures and loading frequencies. The best-fit model that described this relationship was found to be the exponential model as displayed in the figure with high coefficient of

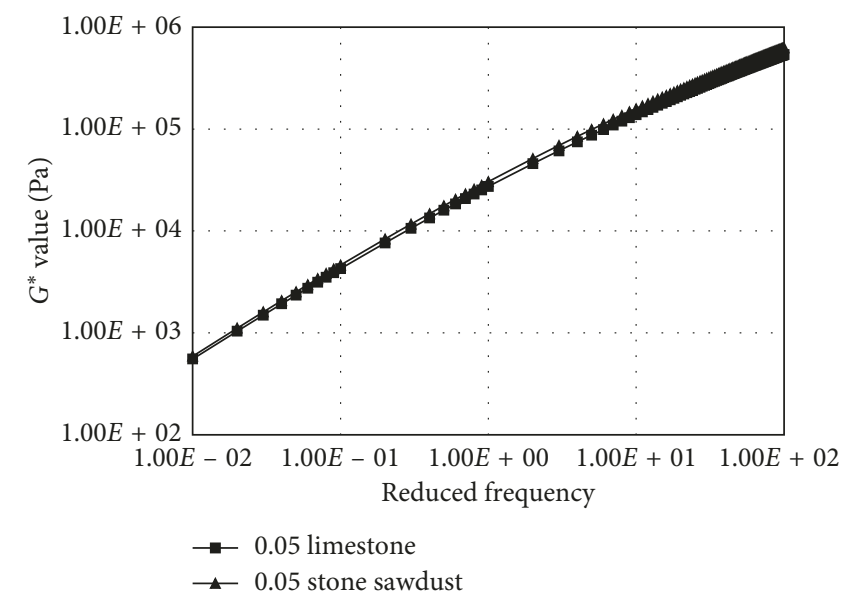

FIgURE 19: $G^{*}$ value master curve for the two mastics $(\mathrm{VR}=0.05)$.

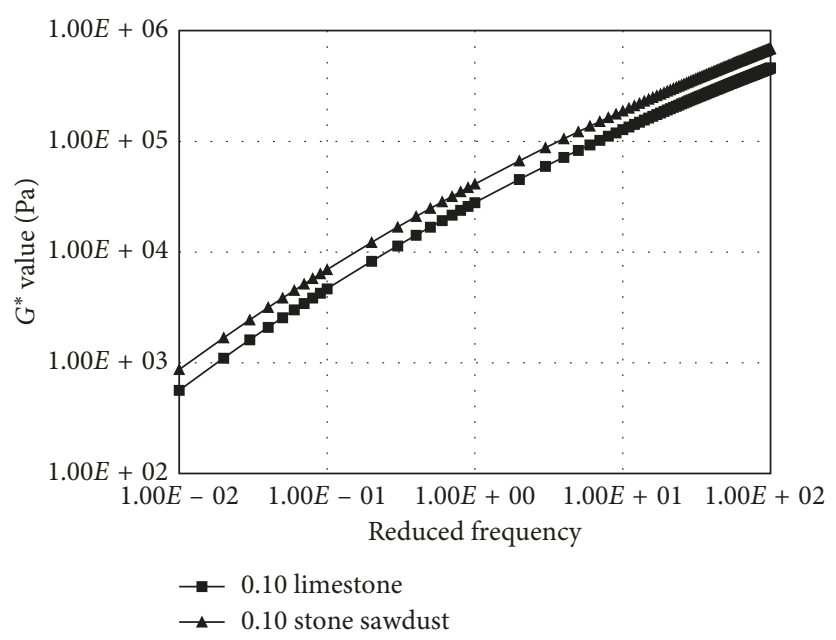

Figure 20: $G^{*}$ value master curve for the two mastics $(\mathrm{VR}=0.10)$.

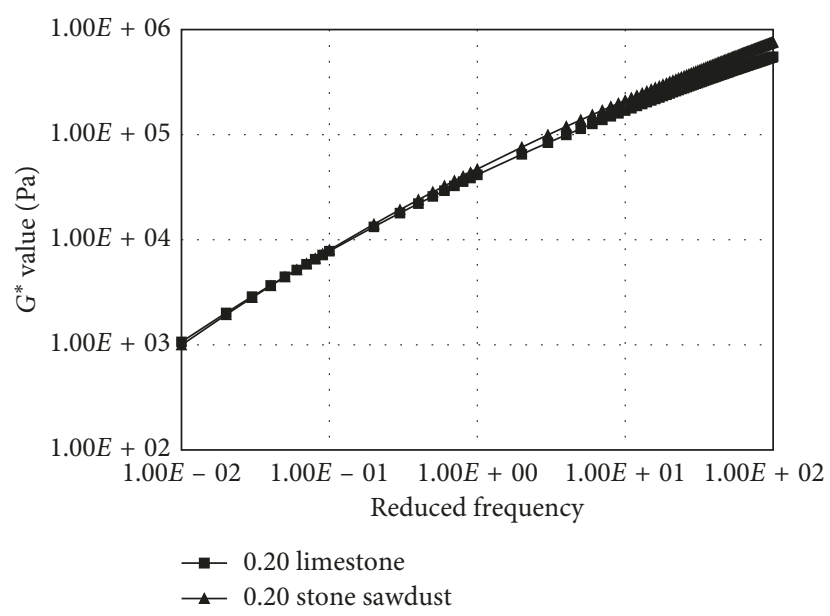

Figure 21: $G^{*}$ value master curve for the two mastics $(\mathrm{VR}=0.20)$.

determination $\left(r^{2}\right)$ for both mastics. This applied to all combinations of the seven temperatures and nine loading frequencies. 


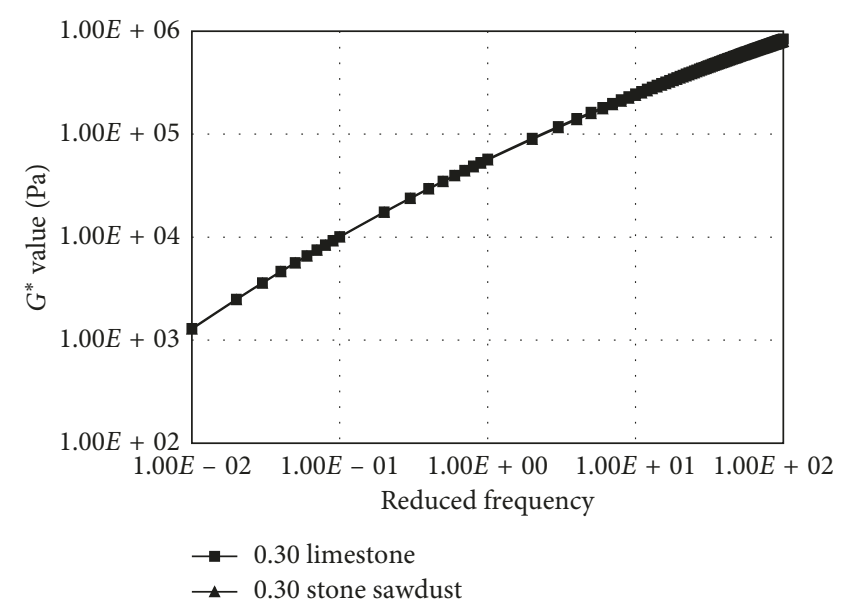

Figure 22: $G^{*}$ value master curve for the two mastics $(\mathrm{VR}=0.30)$.

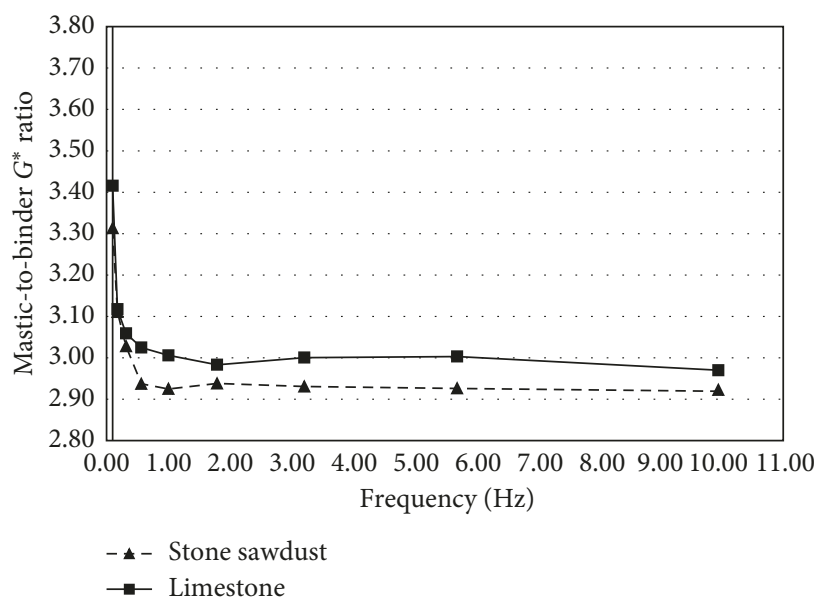

FIGURE 23: Mastic-to-binder modulus ratio versus frequency $\left(T=40^{\circ} \mathrm{C}\right.$ and $\left.\mathrm{VR}=0.30\right)$.

\section{Conclusions}

The analysis and the results of this study revealed the following major conclusions:

(1) The stone sawdust filler showed higher resistance to fatigue than the limestone filler.

(2) The stone sawdust-asphalt mastic also showed higher resistance to rutting than the limestone-asphalt mastic. The relationship between $\left|G^{*}\right| / \sin \delta$ and volume ratio was found to be exponential. The exponential models with the coefficients of determination $\left(r^{2}\right)$ for the two mastics were summarized.

(3) The elastic behavior of the two asphalt mastics increased with the increase in volume ratio. However, the $\left|G^{*}\right| \cos \delta$ values for the stone sawdust and limestone mastics were nearly similar at all frequencies and temperatures. The best-fit model that described the relationship between the volume ratio (VR) and the $\left|G^{*}\right| \cos \delta$ value is the exponential model. The coefficient of determination $\left(r^{2}\right)$ for the model was high in all cases.

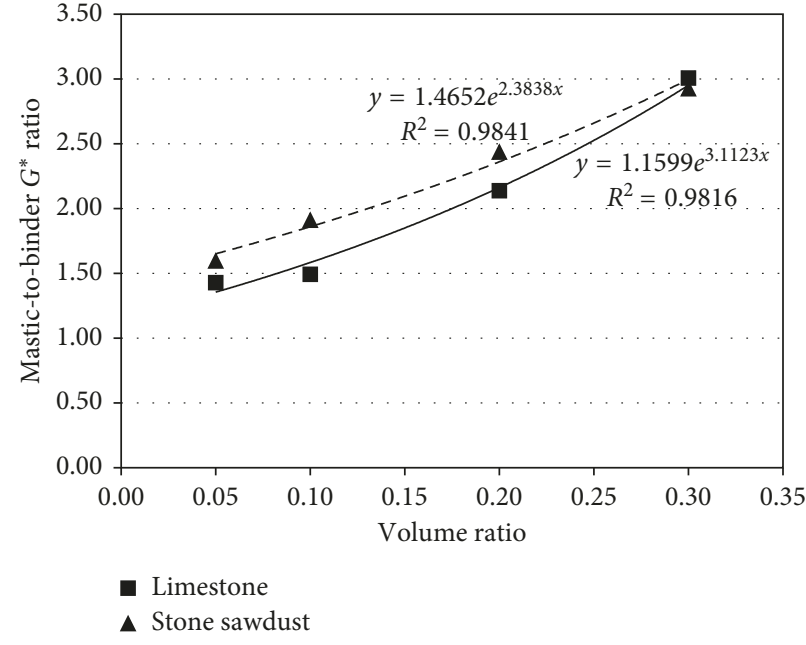

FIGURE 24: Mastic-to-binder modulus ratio versus volume ratio $\left(T=40^{\circ} \mathrm{C}\right.$ and $\left.f=1 \mathrm{~Hz}\right)$

(4) The two fillers showed a typical reduction in the $\left|G^{*}\right| \cos \delta$ value with temperature. Yet, the rate of reduction at lower temperatures was very sharp and significant compared to high temperatures.

(5) The differences in the complex shear modulus $\left(G^{*}\right)$ value between the limestone filler and the stone sawdust filler were found relatively small and insignificant particularly at low loading frequencies and high temperatures.

(6) The mastic-to-binder modulus ratio was found to decrease with the increase in loading frequency at all temperatures and volume ratios. In addition, the modulus ratio increased nonlinearly with the increase in the volume ratio; the best model that described this relationship is the exponential model with a high coefficient of determination $\left(r^{2}\right)$.

\section{Data Availability}

The data used to support the findings of this study are included within the article. Any additional data related to the paper may be requested from the corresponding author.

\section{Additional Points}

Practical Application. The above findings suggest that the waste stone sawdust could replace the limestone filler in asphalt mix production as both materials demonstrated similar mechanical behaviors and trends in this study. Moreover, it is important to mention that the source of the two materials is the same. The limestone filler is part of the limestone crushed in local quarries from limestone rocks, and the stone sawdust is a waste material collected from stonemanufacturing sites for building purposes. For this reason, the other physical properties of the two materials are expected to be the same. In conclusion, this study provides an alternative (the waste stone sawdust filler) for the limestone filler material that is used in the production of hot-mix asphalt. 


\section{Disclosure}

Ghazi G. Al-Khateeb is on leave at University of Sharjah, P.O. Box 27272, Sharjah, UAE.

\section{Conflicts of Interest}

The authors declare that there are no conflicts of interest regarding the publication of this paper.

\section{References}

[1] G. G. Al-Khateeb and K. Z. Ramadan, "Investigation of the effect of rubber on rheological properties of asphalt binders using superpave DSR," Korean Society of Civil Engineers (KSCE) Journal of Civil Engineering, vol. 19, no. 1, pp. 127-135, 2015.

[2] K. Ghuzlan, G. Al-Khateeb, and A. Abu Damrah, "Using oil shale ash waste as a modifier for asphalt binders," Journal of Material Cycles and Waste Management, vol. 15, no. 4, pp. 522-529, 2013.

[3] T. Khedaywi, G. Al-Khateeb, and M. Irfaeya, "Effect of medical ash on shear properties of asphalt binder using superpave dynamic shear rheometer (DSR)," Journal of Solid Waste Technology and Management (JSWTM), vol. 38, no. 1, pp. 19-27, 2012.

[4] T. S. Khedaywi, "Study on utilising waste toner in asphalt cement," Journal of Road Materials and Pavement Design, vol. 15, no. 2, pp. 446-454, 2014.

[5] R. Muniandy, H. Jafariahan, R. Yunus, and S. Hassim, "Determination of rheological properties of bio mastic asphalt," American Journal of Engineering and Applied Sciences, vol. 1, no. 3, pp. 204-209, 2008.

[6] Y. Kim, D. Little, and I. Song, "Effect of mineral fillers on fatigue resistance and fundamental material characteristics: mechanistic evaluation," Transportation Research Record: Journal of the Transportation Research Board, vol. 1832, pp. 34-54, 2003.

[7] T. Yi-qiu, Z.-H. Li, X.-Y. Zhang, and Z.-J. Dong, "Research on high- and low-temperature properties of asphalt-mineral filler mastic," Journal of Materials in Civil Engineering, vol. 22, no. 8, pp. 811-819, 2010.

[8] A. K. Das and D. Singh, "Investigation of rutting, fracture and thermal cracking behavior of asphalt mastic containing basalt and hydrated lime fillers," Construction and Building Materials, vol. 141, no. 15, pp. 442-452, 2017.

[9] G. G. Al-Khateeb and N. M. Al-Akhras, "Properties of Portland cement-modified asphalt binder using superpave tests," Construction and Building Materials, vol. 25, no. 2, pp. 926-932, 2011.

[10] M. Tuncan, A. Tuncan, and A. Cetin, "The use of waste materials in asphalt concrete mixtures," Waste Management and Research, vol. 21, no. 2, pp. 83-92, 2003.

[11] N. Al-Akhras, A. Ababneh, and W. A. Alaraji, "Using burnt stone slurry in mortar mixes," Construction and Building Materials Journal, vol. 24, no. 12, pp. 2658-2663, 2010.

[12] Asphalt Institute (AI) Superpave Series No. 1 (SP1), Superpave Performance Graded Asphalt Binder Specifications and Testing, 2003.

[13] M Irfaeya, Utilizing Superpave Dynamic Shear Rheometer (DSR) to Investigate Asphalt Mastics Behavior Through Micromechanics in Jordan, Master Dissertation, Department of Civil Engineering, Jordan University of Science and Technology, Irbid, Jordan, 2009. 


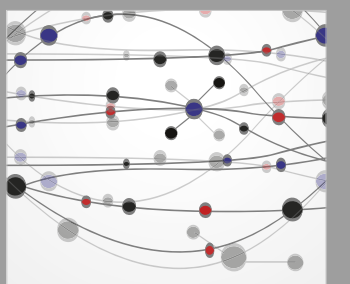

The Scientific World Journal
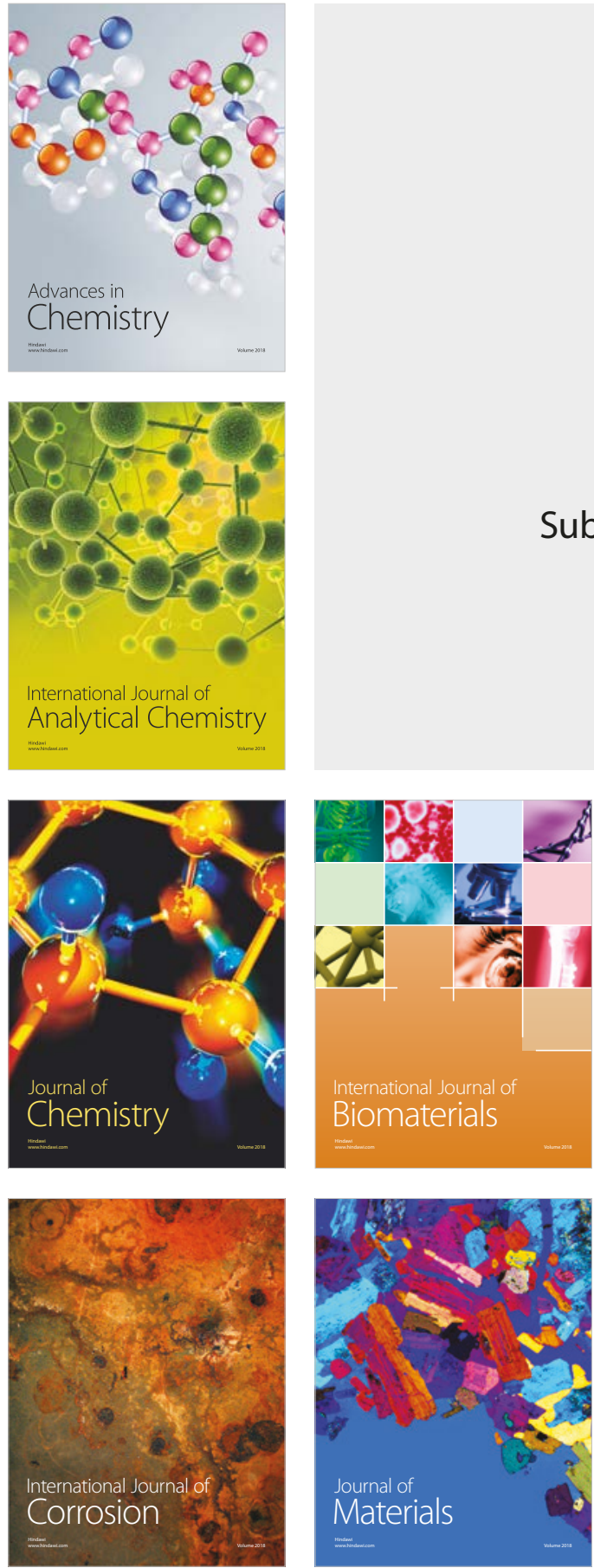

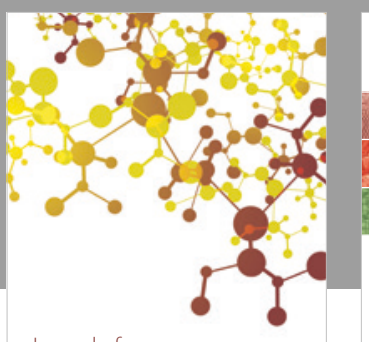

Journal of

Applied Chemistry
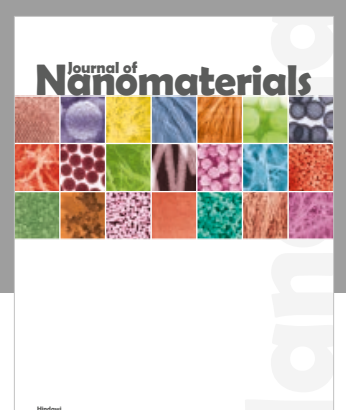

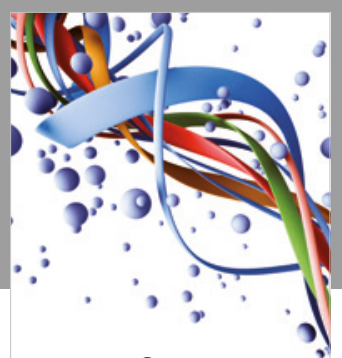

Scientifica

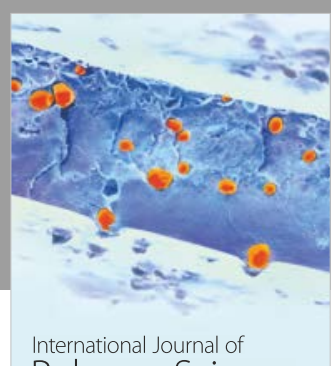

Polymer Science

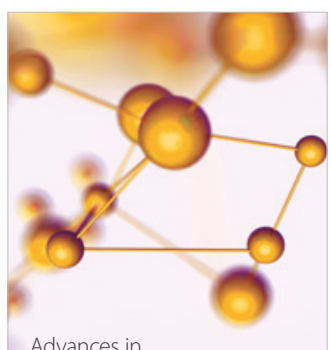

Physical Chemistry
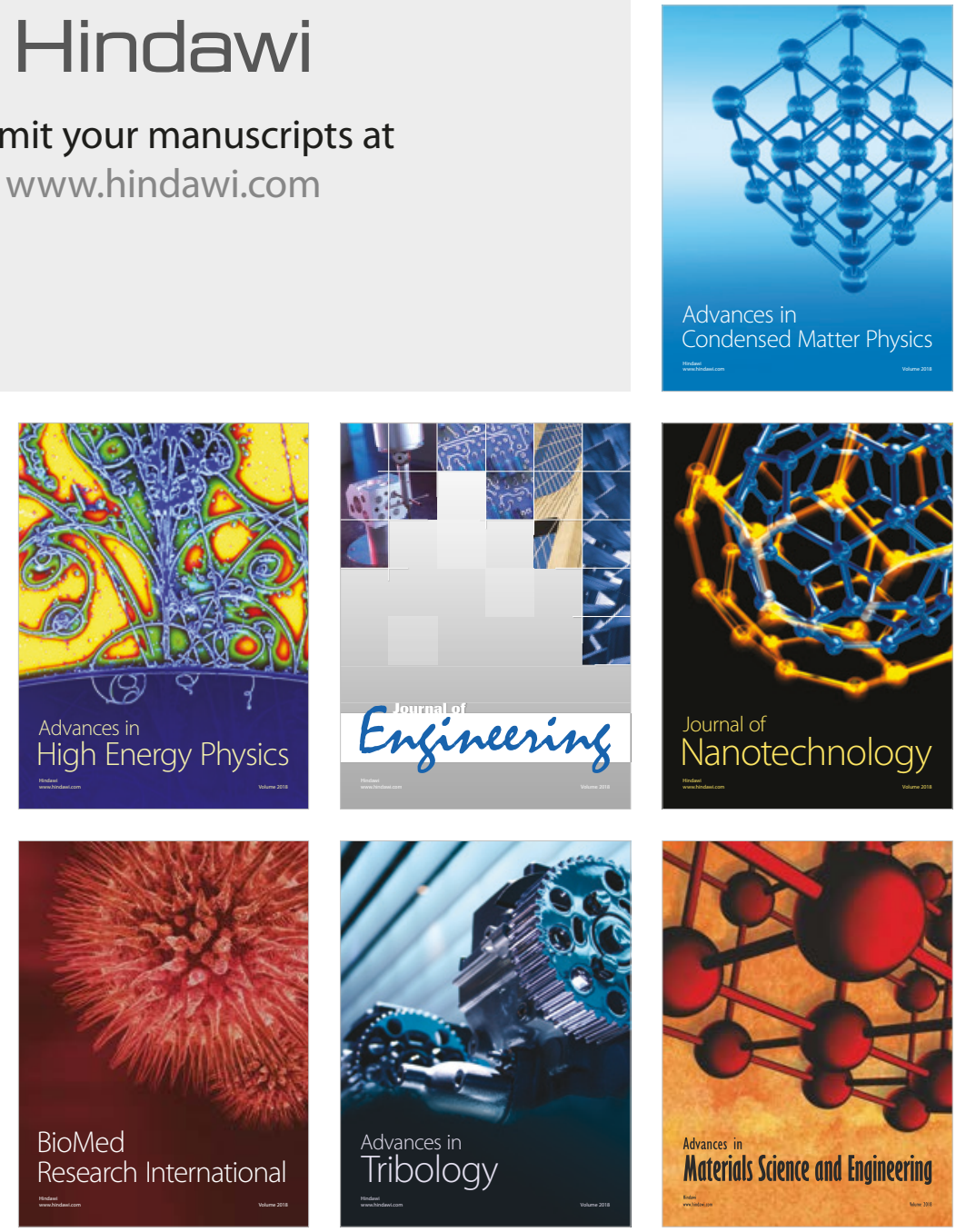